\title{
LA BOMBA ATÓMICA DESPUÉS DE HIROSHIMA Y NAGASAKI. EL DIFÍCIL CAMINO HACIA EL CONTROL DE LA ENERGÍA NUCLEAR
}

The Atomic Bomb after Hiroshima and Nagasaki.

The Difficult Road to Nuclear Power Control

\author{
Carlos Sola Ayape, Tecnológico de Monterrey, México \\ Correo electrónico: csola@tec.mx \\ María Fernanda Sotelo Fuentes, Tecnológico de Monterrey, México \\ Correo electrónico: ma.fernandasotelof@gmail.com
}

Recepción: 23/08/2019

Aceptación: 8/05/2020

Resumen. Si bien es cierto que el lanzamiento de la bomba atómica sobre Hiroshima y Nagasaki, el 6 y el 9 de agosto de 1945, respectivamente, supuso la inmediata rendición de Japón y la finalización de la Segunda Guerra Mundial —el conflicto bélico más devastador de la historia de la humanidad - , el mundo se vio atrapado de inmediato entre la incertidumbre y el miedo como consecuencia del inicio de la era atómica. Dada su trascendencia histórica, en el presente artículo daremos cuenta no sólo del proceso de fabricación de la bomba atómica en el marco del Proyecto Manhattan y de su lanzamiento sobre estas dos ciudades niponas, sino del gran reto que supuso alcanzar un acuerdo para preservar el control atómico en un difícil escenario internacional que pronto desembocaría en la Guerra Fría.

Palabras clave: Bomba Atómica, era atómica, Hiroshima, Nagasaki, Segunda Guerra Mundial.

\begin{abstract}
While it is true that the drop of the atomic bomb on Hiroshima and Nagasaki, respectively, on the $6^{\text {th }}$ and the $9^{\text {th }}$ of August in 1945, the immediate surrender of Japan and the end of the Second World War - the most devastating war conflict in the history of humanity, the world was immediately caught between uncertainty and fear as a result of the beginning of the atomic age. Given its historical significance, in this article we will give account not only of the process of manufacturing the atomic bomb within the framework of the Manhattan Project and its drop on these two Japanese cities, but of the great challenge of reaching an agreement to preserve atomic control in a difficult international scenario that would soon lead to the Cold War.
\end{abstract}

Keywords: Atomic Bomb, atomic age, Hiroshima, Nagasaki, World War II. 
Esta revelación de los secretos de la naturaleza, gracias a Dios ocultada al hombre durante mucho tiempo, debería suscitar las reflexiones más solemnes en el espíritu y la conciencia de todo ser humano que tenga uso de razón.

Winston Churchill, The Times, 7 de agosto de 1945

\section{Introito}

El comandante del Enola Gay, Paul W. Tibetts, nunca se imaginó que aquel avión que pilotaba iba a cambiar de manera trascendental el curso de la historia. Cuando se abrieron las escotillas para liberar la bomba atómica, de nombre Little Boy [niño pequeño], la humanidad no sabía que se encontraba ante el inicio de una nueva época: la era atómica. ${ }^{1}$ Eran las 8:15 horas de la mañana de aquel 6 de agosto de 1945, justo en el momento en que cayó sobre la ciudad nipona de Hiroshima la primera bomba atómica. Decenas de miles de seres humanos murieron en el acto, pagando con su sangre "el costo del parto de la historia". ${ }^{2}$ En ese momento, y conforme al reporte proporcionado por los oficiales estadounidenses, ni siquiera sus mismos creadores tenían un puntual conocimiento del verdadero alcance de semejante invento, ${ }^{3}$ que volvería a ser arrojado, en esta ocasión sobre Nagasaki, tan sólo tres días después.

La bomba atómica desencadenó una sucesión de acontecimientos históricos que marcaron el devenir de aquellos días de agosto de 1945, entre ellos, el final de la Segunda Guerra Mundial y el comienzo de una nueva posguerra sobre la que, de inmediato, caería una larga sombra de dudas y sospechas sobre el futuro inmediato de la energía nuclear. Fue Estados Unidos, creadores del artefacto atómico, los primeros en percatarse de su propia fragilidad en el supuesto de que el secreto de su fabricación podía caer en manos de potencias enemigas, tal y como podía haber sido la Alemania de Hitler o, más adelante, la URSS de Stalin. Por eso, y de las muchas lecturas que puede hacerse de aquella coyuntura histórica, una de ellas destaca sobremanera, a saber: la imperiosa necesidad de Estados Unidos y sus aliados cercanos,

\footnotetext{
${ }^{1}$ En palabras de Henry Smyth, "el principio de la operación de una bomba atómica o de una planta eléctrica basada en la fisión del uranio es relativamente sencillo". Henry Smyth, La energía atómica para fines militares (México: Universidad Autónoma Metropolitana, 1995), 60.

${ }^{2}$ Víctor Manuel Baltazar Ayala, La era atómica (Guanajuato: Imprenta Universitaria, 1996), 6.

${ }^{3}$ John Finney, introducción a Hiroshima: veinte años después (México: Editorial Novaro, 1966), 10.
} 
principalmente Gran Bretaña y Canadá, por establecer un férreo control informativo sobre la fabricación de aquel artefacto devastador y de asegurar, por encima de todo, el secreto atómico.

Por su importancia, éste será el tema central del presente artículo que vertebraremos en dos grandes apartados: en el primero, se presentará una visión en conjunto de la fabricación de la bomba atómica por parte de los Estados Unidos, de los pormenores de su lanzamiento sobre Hiroshima y Nagasaki, así como de la conmoción mundial que generó el conocimiento de su devastador impacto; en el segundo, se analizará el problema del control de la energía nuclear que se generó a partir de entonces, haciendo hincapié en las grandes dificultades para decidir quién o quiénes debían hacerse cargo del control de semejante artefacto científico y militar. En el apartado final, haremos eco de algunas valoraciones con respecto a la naturaleza de este arma mortal y lo que esto implicó para la humanidad en aquel ensamble histórico que pronto desembocaría en una larga Guerra Fría.

\section{El lanzamiento de la bomba y el inicio de la era atómica}

La bomba atómica se gestó en el ámbito de la comunidad científica. Expertos en física nuclear como Eugene Paul Wigner y Leó Szilárd — ambos judíos de procedencia húngara— estaban convencidos de las posibilidades reales de fabricar una nueva bomba, partiendo de los grandes avances experimentados en torno a la fisión del átomo. Conscientes de sus insondables repercusiones, no ocultaron su preocupación acerca de los progresos científicos que, en materia nuclear, se venían obteniendo en los laboratorios de la Alemania nazi, llegando, incluso, a la conclusión de que un arma tan poderosa podía guiar a Adolf Hitler a la consecución de su sueño de dominación mundial. Alertados por esta circunstancia, decidieron invitar a uno de los científicos estelares del momento, por otra parte, enemigo acérrimo del nazismo: Albert Einstein. Previa aceptación, y como integrante del equipo de investigación, Einstein fue uno de los firmantes de una carta, junto con otros hombres de ciencia, como Enrico Fermi o el propio Szilárd, que fue remitida a Franklin D. Roosevelt con fecha de 2 de agosto de 1939. Grosso modo, en la misma hacían saber al presidente estadounidense de su puntual conocimiento de los últimos resultados obtenidos por científicos como Fermi y Szilárd, lo que le llevaba a la conclusión de que el uranio 
podía convertirse "en una nueva e importante fuente de energía en el futuro inmediato". Más allá de esta observación, Einstein ponía el acento sobre "ciertos aspectos” que habían surgido "de la situación” y que, por su gravedad, parecían necesitar de una "vigilancia especial" y de "una rápida acción por parte de su gobierno". En materia de argumentos, y recordando los hallazgos científicos obtenidos por Frédéric Joliot-Curie, en Francia, y de Fermi y Szilárd, en Estados Unidos, advertía de la posibilidad de “provocar una reacción en cadena en una gran masa de uranio, por medio de la cual se generará una vasta cantidad de energía y gran cantidad de nuevos elementos semejantes al radio”. Por todo ello, Einstein estaba convencido de que "tal cosa se logrará en el futuro inmediato" y que, por consiguiente, podían "construirse bombas de un nuevo tipo, en extremo poderosas". 4

Conocedor de tan privilegiada información, el presidente Roosevelt estuvo de acuerdo con el proyecto propuesto por la comunidad científica, convencido de que los resultados obtenidos podían generar un alto impacto, de entrada, en el posterior devenir de la Segunda Guerra Mundial. Con su visto bueno, se daba inicio al llamado Proyecto Manhattan, una iniciativa macro estadounidense apoyada por Gran Bretaña y Canadá. En sus comienzos, nadie podía imaginar cuál habría de ser el resultado final, ni mucho menos que Japón habría de ser el blanco donde sería arrojada la primera bomba atómica, una mañana de agosto de 1945. Desde el principio, todo parecía indicar que el objetivo militar sería Alemania. Al morir el presidente Roosevelt, el 12 de abril de 1945, Harry S. Truman asumiría la presidencia de los Estados Unidos, convirtiéndose, en consecuencia, en el jefe de Estado que habría de tomar las decisiones finales. ${ }^{5}$

El Proyecto Manhattan representó el proyecto científico, tecnológico, militar y económico más ambicioso de Estados Unidos en el marco de la segunda gran guerra. Con el mismo, el presidente Truman, un político inexperto en cuestiones internacionales, se encontró con una carta escondida, especialmente después de que el 16 de julio de 1945 fuera exitoso el ensayo de explosión de la primera bomba atómica, en un enclave de Nuevo México

\footnotetext{
${ }^{4}$ Ralph E. Lapp, "La carta de Einstein”, en Hiroshima, 24.

5 "Harry S. Truman, de 60 años, no sabía casi nada acerca del Proyecto Manhattan ni de su potencial para ganar la guerra. Sin embargo, en las primeras 24 horas de su presidencia fue informado por el secretario de Guerra, Henry L. Stimson, quien le habló 'del desarrollo de un nuevo explosivo con un poder destructivo casi increíble"'. Diana Preston, Antes de Hiroshima: De Marie Curie a la bomba atómica (México: Sevilla Editores, 2008), 325 .
} 
llamado Álamo Gordo. ${ }^{6}$ Según dieron cuenta los testigos, la primera señal recibida fue un intenso resplandor de luz blanca que iluminó el desierto con una intensidad 20 veces mayor que la luz del sol del mediodía. Acto seguido, y durante 50 eternos segundos se escuchó un extraño silencio, que dio paso a un contundente estruendo que terminó siendo tranquilizador. ${ }^{7}$ Conforme a un informe oficial estadounidense de 1946, encargado por el general Leslie Richard Groves - el alto mando militar que tuvo a su cargo el Proyecto Manhattan- y redactado por Henry de Wolf Smyth — presidente del departamento de Física de la Universidad de Princeton-, el ensayo en Álamo Gordo dejó esta primera sensación colectiva: "Todos parecieron sentir que se hallaban presentes en el nacimiento de una nueva era - la Era Atómica - y sintieron su profunda responsabilidad en ayudar a guiar por los justos cauces las fuerzas tremendas que habían sido liberadas por primera vez en la historia". 8

A pesar del éxito obtenido en Álamo Gordo, para junio de 1945 la bomba atómica era un elemento desconocido. Los cerca de 150,000 empleados que trabajaban en el Proyecto Manhattan permanecían inmersos en la incertidumbre. Durante la guerra, particularmente, desde diciembre de 1941, cuando Estados Unidos entró en el conflicto, el Proyecto Manhattan se expandió a un ritmo acelerado, sumando multitud de esfuerzos de técnicos, ingenieros y científicos norteamericanos y británicos, así como de refugiados, especialmente, judíos que habían huido de Europa de las invasiones nazis. Su sentido de misión y hasta de urgencia estaban más que fundados. Washington tenía conocimiento de que los científicos nazis venían trabajando sobre el principio de los explosivos fisionables, por lo que existía el riesgo de que Alemania pudiera ser la primera en obtener la bomba atómica, en cuyo el caso, el mundo podía verse amenazado por la hegemonía hitleriana. De ahí que fuese Alemania, no Japón, el blanco original del Proyecto Manhattan. ${ }^{9}$ El devenir de los acontecimientos, especialmente tras la derrota

\footnotetext{
${ }^{6}$ En el informe de la Secretaría de Guerra estadounidense se decía lo siguiente: "Un arma revolucionaria, instalada en una torre de acero y destinada a cambiar la guerra tal y como la conocemos, o que inclusive podría convertirse en el instrumento para poner fin a todas las guerras, se hizo estallar con tal impacto que marcó la entrada de la humanidad a un nuevo mundo físico". Smyth, La energía atómica, 361.

${ }_{8}^{7}$ Excélsior, 28 de abril, 1982, 3.

${ }^{8}$ Henry de Wolf Smyth, La energía atómica al servicio de la guerra: informe oficial del desarrollo de la bomba atómica realizado con el patrocinio del gobierno de los Estados Unidos durante el periodo 1940-1945 (México: Espasa Calpe, 1946), 311.

${ }^{9}$ Hanson W. Baldwin, "La decisión sobre Hiroshima", en Hiroshima, 41 y 42.
} 
alemana en Normandía (30 de agosto de 1944) y la posterior caída de Berlín (2 de mayo de 1945), desviaron el eje estratégico hacia el imperio del sol naciente. La selección de blancos fue resultado de varias reuniones y, finalmente, el llamado Comité de Objetivos redactó una lista negra que incluía cuatro ciudades japonesas: Kokura, Hiroshima, Niigata y Kioto. ${ }^{10}$

El 24 de julio de 1945, desde Washington, se mecanografió un cuadro de instrucciones para el comandante general de la Fuerza Aérea Estratégica de Estados Unidos, el general Karl Spaatz, quien había reclamado un documento oficial con reglas precisas para ejecutar el lanzamiento de la bomba atómica. ${ }^{11}$ Mientras tanto, Estados Unidos pudo a remitir un nuevo ultimátum a Japón por medio de la llamada Declaración de Potsdam. ${ }^{12}$ Era el 26 de julio, y en la misma se exigía al gobierno japonés su rendición incondicional, bajo la amenaza de su “destrucción rápida y absoluta". ${ }^{13}$ En esta declaración, firmada por Truman, Churchill y Chiang Kai-Shek — de Estados Unidos, Reino Unido y República de China, respectivamente-, y que después suscribió la URSS de Stalin, no se establecía una postura clara sobre lo que sucedería con la figura del emperador nipón, pero no había duda de que Japón perdería todas sus conquistas. El comunicado generó una profunda división entre la sociedad nipona, principalmente, entre militares y políticos: mientras que los primeros querían seguir en la lucha hasta el final, los segundos se mostraban partidarios de que Japón pusiera fin a la guerra. La decisión última fue anunciada el 30 de julio. Ese día, el periódico The New York Times publicaba la noticia de que Japón había declinado el ultimátum aliado y que, por consiguiente, no estaba dispuesto a firmar su rendición. ${ }^{14}$

La negativa nipona activó de inmediato el plan norteamericano y el presidente Truman tomó la decisión de usar la bomba en contra de Japón. ${ }^{15}$ El 5 de agosto, el coronel

\footnotetext{
${ }^{10}$ De la lista negra, el secretario de Guerra Stimson dio prioridad a Nagasaki en vez de Kioto. Ibid., 43.

${ }^{11}$ La orden decía: "El Grupo Compuesto 509, de la 20 Fuerza Aérea, lanzará la primera bomba especial en cuanto el tiempo permita visibilidad para el bombardeo después del 3 de agosto de 1945, en uno de los blancos: Hiroshima, Kokura, Niigata y Nagasaki”. Ibid., 48.

${ }^{12}$ El Universal, 8 de agosto, 1945, 1 (segunda parte).

${ }^{13}$ La declaración decía: "Nos dirigimos al gobierno del Japón para que proclame de inmediato la rendición incondicional de todas las fuerzas armadas japonesas, y que proporcione garantías propias y adecuadas de su buena fe en tal acción. La alternativa para el Japón es la destrucción rápida y absoluta". Baldwin, "La decisión sobre Hiroshima", 50.

${ }^{14}$ Ibid., 51 y 52.

${ }^{15}$ Acerca de los pormenores en torno al lanzamiento de las dos bombas atómicas, véase Len Giovannitti y Fred Freed, La decisión de lanzar la bomba (Barcelona: Editorial Diana, 1968), 98-107.
} 
Paul W. Tibbets estaba ya listo para pilotar el primer vuelo atómico de la historia en una aeronave que bautizó con el nombre de su madre —Enola Gay_, la misma que cargaría a Little Boy, la primera y gran bomba atómica de 4.5 metros de largo, 1.5 metros de diámetro y 5 toneladas de peso. ${ }^{16}$ Al día siguiente, 6 de agosto de 1945, a las dos con cuarenta y cinco de la mañana, el Enola Gay inició su viaje hacia territorio nipón, partiendo de la Isla de Tinian —ubicada a unas seis horas de Japón-, con la única misión de arrojar aquel artefacto atómico. A las 8:15 de la mañana, y estando el avión a 10,000 metros de altura sobre una despreocupada Hiroshima, se lanzó el instrumento de destrucción más aterrador que hasta entonces había producido el hombre, una bomba atómica que transportaba en sus entrañas una fuerza explosiva de más de 20000 toneladas de TNT o trinitrotolueno. Con un intenso resplandor, Hiroshima quedaba oculta en una enorme bola de fuego de color violeta y un humo convulsivo. ${ }^{17}$ Según testimonios de la tripulación, sólo vieron polvo, llamas y una inmensa nube con la forma perfecta de un hongo. ${ }^{18}$

Al día siguiente, los periódicos de todo el mundo se hicieron eco de la noticia, aun sin tener certeza alguna sobre los efectos provocados por una bomba de la que todos hablaban. ${ }^{19}$ Eran momentos de una gran confusión. Lo único que se sabía era que la bomba había sido arrojada sobre la ciudad nipona de Hiroshima, la cual había quedado envuelta en polvo y humo, y que no había forma de valorar lo que estaba sucediendo allí. ${ }^{20}$ Así, y a modo de ejemplo, en México no fue hasta el 8 de agosto cuando el periódico Excélsior sacó la noticia de que la ciudad había sido escogida no por su importancia estratégica, sino por sus condiciones meteorológicas, al disfrutar de un tiempo despejado y unas condiciones de visibilidad idóneas para observar con claridad la magna explosión. ${ }^{21}$

El 9 de agosto salieron a la luz los primeros reportes acerca de los devastadores efectos de la bomba atómica. Así, se daba cuenta de la destrucción del más del 60 por ciento de

\footnotetext{
${ }^{16}$ Baldwin, "La decisión sobre Hiroshima”, 53.

17 "La pika — palabra que en japonés significa luz- es el nombre que los habitantes de Hiroshima dieron al monstruo que les cayó del cielo". Fernand Gigon, Horror en cadena: apocalipsis del átomo (Barcelona: Seix Barral, 1960), 33.

${ }^{18}$ Baldwin, "La decisión sobre Hiroshima", 55.

19 "Truman anuncia el empleo de la bomba atómica", Excélsior, 7 de agosto, 1945, 1.

20 "Son desatados por la bomba atómica norteamericana", Excélsior, 7 de agosto, 1945, 1.

${ }^{21}$ Uno de los titulares de Excélsior no podía ser más expresivo: "Desaparecieron mil manzanas de casas por la bomba atómica", Excélsior, 8 de agosto, 1945, 1.
} 
Hiroshima, con una población de 343000 personas donde prácticamente todas ellas habían sido exterminadas. ${ }^{22}$ Días después del lanzamiento, se tuvo conocimiento de unas declaraciones del coronel Tibbets, el piloto de la súper fortaleza B-29 que dejó caer la primera bomba atómica sobre Hiroshima:

Apenas podíamos creer lo que estábamos viendo. [...] Hiroshima tembló como si fuera sacudida por un terrible terremoto. [...] arrojamos la primera bomba atómica a las 8.15 horas tiempo de Japón. [...] una inmensa nube de humo se levantó y cubrió por completo a Hiroshima. La explosión nos produjo la misma sensación que se experimenta cuando cerca del aeroplano estallan los proyectiles de las balas antiaéreas y forman un vacío que hace cabecear el aparato. ${ }^{23}$

Más allá de las impactantes escenas, lo cierto es que Estados Unidos tenía la certeza de que la bomba atómica acortaría la guerra. Al día siguiente de Hiroshima, el secretario de Guerra estadounidense, Henry L. Stimson, declaró lo siguiente: "Es perfectamente claro que la posesión por Estados Unidos de tan poderosa arma, aun en su forma actual, constituirá una ayuda tremenda para acortar la guerra". Con esta declaración de intenciones, avanzaría después algunos pormenores de su fabricación: "La primera bomba atómica fue arrojada sobre el Japón a las tres semanas justas de que fue sometida a su prueba inicial en un sitio apartado de la base aérea de Álamo Gordo, a 190 kms al S. E. de Albuquerque, Nuevo México". ${ }^{24}$ Sin embargo, y más allá de las previsiones, Estados Unidos se llevó la sorpresa al conocer la noticia de que los japoneses, lejos de rendirse, seguían en pie de lucha. El 9 de agosto, una segunda bomba atómica, conocida como Fat Man [hombre gordo], fue arrojada sobre la ciudad nipona de Nagasaki, matando a unas 40,000 personas y dejando un saldo de más de 60,000 heridos. ${ }^{25}$

Los periódicos mexicanos Excélsior y El Universal dieron la noticia ese mismo día, haciendo eco de la gran conmoción mundial que había generado el lanzamiento de una nueva bomba atómica sobre otra población nipona, una ciudad de gran importancia estratégica situada en la parte occidental de la Isla de Kyushu. ${ }^{26} \mathrm{Si}$ bien los efectos fueron diferentes en ambas

\footnotetext{
22 "No hay detalles de los estragos de esta bomba", Excélsior, 9 de agosto, 1945, 1.

${ }^{23}$ El Universal, 8 de agosto, 1945, 1.

${ }^{24}$ El Universal, 7 de agosto, 1945, 10.

${ }^{25}$ Baldwin, "La decisión sobre Hiroshima", 55. El periódico señaló que, a pesar de las múltiples víctimas ocasionadas, la bomba atómica serviría para "ahorrar vidas norteamericanas y japonesas". "Se cree que la rendición del Japón es cuestión de semanas", Excélsior, 8 de agosto, 1945, 9.

26 "No hay detalles de los estragos de esta bomba", Excélsior, 9 de agosto, 1945, 1.
} 
ciudades — el conglomerado urbano de Nagasaki era mayor que el de Hiroshima—, ${ }^{27}$ ambas padecieron la misma situación de dolor, angustia, caos e incertidumbre. El cuadro era de tal de confusión que no era posible ni siquiera precisar el número de muertes. ${ }^{28}$ Para el 12 de agosto se comprobaba lo que ya se temía: el grado de destrucción de Nagasaki era mayor que en Hiroshima, tal y como quedaría confirmado por el general Thomas P. Farrell, comandante de operaciones de la bomba atómica. ${ }^{29}$ Como reportó Excélsior, el 30 por ciento de Nagasaki había quedado destruida en el bombardeo atómico. ${ }^{30}$

El lanzamiento de ambas bombas atómicas sobre Japón trajo de inmediato las primeras consecuencias. Así, El Universal reportaba sobre Hiroshima — séptima de las ciudades japonesas - que había quedado "virtualmente borrada del mapa a causa del cataclismo provocado por una sola bomba atómica arrojada por los americanos y cuyos efectos deshicieron los edificios cual si fuesen castillos de naipes y no dejaron huella de vida animal en todo su radio de acción”. Haciendo eco de las emisiones de Radio Tokio, se hacía saber que Hiroshima era "un tristísimo panorama de ruina y desolación", y que la importante base de aprovisionamientos del ejército imperial nipón no era "más que destrucción y muerte". 31 Por su parte, Excélsior daba cuenta de que las casas y los demás edificios habían quedado "aplastados, y todos los muertos y heridos recibieron quemaduras tales que fue imposible reconocerlos". ${ }^{32}$ Semanas más tarde, se dijo que, con el fin de evitar que la radioactividad producida por los rayos $\mathrm{X}$ envenenara la tierra, las bombas arrojadas sobre Hiroshima $\mathrm{y}$ Nagasaki se hicieron estallar a gran altura del suelo, evitando además que no hubiese guerra química indirecta a causa del envenenamiento de la tierra por los elementos radioactivos, ni más horrores que los habituales ocasionados por cualquier gran explosión. ${ }^{33}$

En cuanto a las repercusiones para la salud, de inmediato se detectó que los rayos de referencia afectaban extrañamente a la sangre y hacían a sus víctimas presa de una funesta infección. La mayor parte de las personas que se hallaban en un radio de acción de un kilómetro y medio del centro de la explosión, murieron rápidamente, bien a causa

\footnotetext{
27 Ibidem.

${ }^{28}$ Ibidem.

29 "Ya se perfeccionó la bomba", Excélsior, 12 de agosto, 1945, 1.

30 "Casi la tercera parte de la industrial ciudad de Nagasaki ha desaparecido”, Excélsior, 11 de agosto, $1945,1$.

${ }^{31}$ El Universal, 9 de agosto, 1945, 1.

32 "No quedó un solo ser vivo en Hiroshima", Excélsior, 9 de agosto, 1945, 1.

33 "Primeras revelaciones que se hicieron en Álamo Gordo, N. M.", Excélsior, segunda sección, 12 de septiembre, 1945, 12.
} 
del intenso calor, bien por las heridas sufridas al derrumbarse los edificios por la onda expansiva. Muchos de los que escaparon de la muerte, perecieron después como consecuencia de los efectos de los rayos parecidos a los del radio. Según daba cuenta Excélsior, la sangre no coagulaba, sino que "brotaba por muchos lugares de la piel, aunque no haya padecido lesión ninguna”. A su vez, desaparecían los glóbulos blancos, “que combaten la infección y, a falta de éstos, prosperaba la infección” y el paciente moría "generalmente dos o tres semanas después de haber estado expuesto a los rayos". 34 Muchas personas padecían "trastornos digestivos y se les caía el cabello y los dientes". Los médicos explicaron que el exceso de rayos $\mathrm{X}$ generaba la caída de cabello, habitualmente en forma transitoria, y que, a su vez, produce trastornos estomacales. ${ }^{35} \mathrm{~A}$ todo esto, se sumó una fuerte conmoción interna originada por la derrota y el hambre. ${ }^{36}$

Los cuestionamientos éticos y morales no se hicieron esperar. De inmediato, los periódicos se preguntaron si los norteamericanos debieron usar gases en contra de los japoneses, y algunos periódicos estadounidenses se cuestionaron si los bombardeos eran necesarios. Por ejemplo, en el diario Evening Star, de Washington D. C., se mencionó que el lanzamiento de la bomba atómica no fue tan eficiente como debía ser, así como la creación de problemas morales y políticos tanto para el ganador como para el perdedor dada la cantidad de vidas, que murieron en ese momento. ${ }^{37}$ No hay que olvidar que los más fervientes partidarios de su utilización defendieron la tesis de que era el arma contra los aviones nipones. $^{38}$ En cambio, algunos científicos que trabajaron en secreto en el Proyecto Manhattan, especialmente hombres como Szilárd, objetaron vigorosamente al uso del arma atómico en contra de la población civil. ${ }^{39}$ Por otra parte, se justificaba el uso de la bomba atómica al argumentar que era necesario para lograr la rendición de los japoneses, que eran tildados de ser "un grupo de fanáticos enloquecidos, ya que la psicología del oriental era algo misterioso". 40 Desde las páginas de Excélsior, el periodista y exiliado español Luis

\footnotetext{
34 "Fantásticos efectos de los rayos que emiten las bombas atómicas", Excélsior, 7 de diciembre, $1945,2$.

35 "Primeras revelaciones", 12.

36 “Se forma en Japón un gabinete liberal”, Excélsior, 8 de octubre, 1945, 1.

${ }^{37}$ Evening Star, 4 de noviembre, 1945, 9.

${ }^{38}$ Corl Palmer, "Atómica y gases", Excélsior, 11 de agosto, 1945, 3.

${ }^{39}$ Lapp, "La carta de Einstein", 32.

${ }^{40}$ Fletcher Pratt, “A qué se atiene el Japón”, Excélsior, 7 de agosto, 1945, 3.
} 
Araquistáin avanzaba una gran reflexión: "Lo que sí fue cierto, es que esta dichosa o maldita bomba nos transportó, con la velocidad fabulosa de sus protones y neutrones, a lejanas edades futuras, haciéndonos vivir con la imaginación intuitiva en mundos venideros que no podrán ver nunca nuestros efímeros ojos físicos". 41

El 10 de agosto, cuatro días después del lanzamiento de la primera bomba atómica, y tan sólo uno después de la segunda, Japón envió su primera oferta de rendición por medio del diplomático suizo Max Grässli al secretario de Estado estadounidense James F. Byrnes. Con este gesto se daba inicio a las negociaciones que llevarían a la rúbrica de la rendición incondicional de Japón frente a las fuerzas aliadas y con ello poner fin a la Segunda Guerra Mundial. ${ }^{42}$ En la misiva, Japón pidió “el cese sin demora de las hostilidades”, con el fin de "salvar a la humanidad de las calamidades que supondrían una continuación de la guerra" y subrayó la voluntad de "su Majestad, el emperador [...de...] apoyar la causa de la paz mundial". El acuerdo definitivo quedó cerrado cinco días después, aunque no fue hasta el 2 de septiembre cuando el ministro de Exteriores japonés, Mamoru Shigemitsu, firmó la rendición incondicional en nombre del emperador Hirohito - los aliados lo bautizaron como el Día de la Victoria sobre el Japón-, mientras que el general estadounidense Douglas MacArthur retransmitía la capitulación por radio desde el U.S.S. Missouri, fondeado en la Bahía de Tokio. ${ }^{43}$

Consumada la rendición nipona, comenzó a circular en diversos medios la idea de que la guerra había terminado. ${ }^{44}$ El teniente nipón Maketo Tamaki señaló que la bomba atómica

\footnotetext{
${ }^{41}$ Luis Araquistáin, “Intermedio de la bomba atómica”, Excélsior, 11 de septiembre, 1945, 4.

42 Japón aceptaba la Declaración de Potsdam bajo el entendimiento de que ésta no implicara demanda alguna que perjudicara las prerrogativas de Su Majestad Hirohito como gobernante soberano. En Baldwin, "La decisión sobre Hiroshima", 56.

${ }^{43}$ La rendición de Japón decía así: "El Cuartel General Imperial, por instrucciones del Emperador y de conformidad con la rendición, ante el Comandante Supremo de las Potencias Aliadas, de todas las fuerzas armadas japonesas, ordena por la presente a todos sus comandantes en el Japón y en el extranjero que obliguen a las fuerzas armadas japonesas y demás fuerzas dominadas por los japoneses, que cesen las hostilidades inmediatamente, que depongan las armas, que permanezcan en donde se hallan y que se rindan incondicionalmente a los comandantes que representen a los Estados Unidos, la República de China, el Reino Unido, el Imperio Británico y la Unión de Repúblicas Soviéticas Socialistas, tal como se indica aquí o lo disponga después el Comandante Supremo de las Potencias Aliadas". "Primera Orden General de la Rendición", en Excélsior, 2 de septiembre, 1945, 1.

${ }^{44}$ En el periódico El Universal se publicó lo siguiente: "Terminada la guerra no debe haber vencedores ni vencidos, sino hombres fraternalmente unidos en un infinito anhelo de paz, y no ya de posibilidad, sino de seguridad de mutua convivencia [...]. La voluntad de paz, el aseguramiento de la paz, descansará de aquí en
} 
había supuesto un "golpe demoledor al Japón". ${ }^{45}$ Con la aceptación de Potsdam, Japón perdía el lugar que ocupaba en el mundo como resultado del ataque de Pearl Harbor. Su territorio quedó reducido a sus cuatro islas metropolitanas — Kiushu, Shikuko, Honshu y Hokkaido-_, más otras que fueron designadas por los aliados. ${ }^{46}$

La finalización de la Segunda Guerra Mundial dejó las primeras consecuencias: la creación de las Naciones Unidas y la emergencia de los Estados Unidos y la Unión Soviética como dos superpotencias por reunir los elementos militares, económicos y políticos suficientes para disputarse el destino de la humanidad. ${ }^{47}$ Dentro de la comunidad científica, las recriminaciones, los arrepentimientos y el sentimiento de culpa germinaron entre algunos científicos y otras personalidades de gobierno a principios de $1945 .{ }^{48}$ Pero también se empezó a gestar la idea de que el descubrimiento de métodos para la desintegración del átomo podía abrir las puertas del progreso a la ciencia "tan radicales en algunas fases de la vida humana que sobrepasaba cuanto la imaginación puede fantasear". ${ }^{49}$ El hecho de poder valernos de la energía atómica presentó una nueva era en el entendimiento de las fuerzas de la naturaleza por el hombre. ${ }^{50}$ Esto provocó que fuera difícil predecir hasta qué punto se usaría la bomba atómica como un arma en reserva para sofocar la amenaza que representarían los incidentes del futuro. ${ }^{51}$

Las reacciones alrededor del mundo no se hicieron esperar. En México, por ejemplo, el presidente Manuel Ávila Camacho declaró que, una vez terminada la guerra, la aspiración debía ser la construcción de una paz "segura, perdurable, próspera y noble". ${ }^{2}$ Por parte de la comunidad científica, Robert Oppenheimer, uno de los físicos artífices de la bomba atómica,

\footnotetext{
adelante en la unanimidad de las almas; será cuestión espiritual y universal, antes que social y política". El Universal, 11 de agosto, 1945, 3.

${ }^{45}$ En palabras de Keith Wheeler, los japoneses no querían hablar más de la guerra, "totalmente liquidada para ellos", Excélsior, 1 de septiembre, 1945, 1 (segunda sección).

${ }^{46}$ El Universal, 12 de agosto, 1945, 1.

47 "El nacimiento de las Naciones Unidas tuvo lugar en la reunión celebrada entre el primer ministro británico Winston Churchill y el presidente de los Estados Unidos Franklin D. Roosevelt, en agosto de 1941, quienes suscribieron una declaración conjunta conocida como la Carta del Atlántico". Baltazar, La era atómica, 8.

${ }^{48}$ Baldwin, "La decisión sobre Hiroshima", 57.

${ }^{49}$ Véase, por ejemplo, "La desintegración atómica puede lograr la juventud perpetua", en Excélsior, 20 de octubre, 1945, 1 (segunda sección).

50 "Truman anuncia el empleo de la bomba atómica", Excélsior, 7 de agosto, 1945, 1.

51 "La bomba atómica neutraliza el polvorín balcánico", Excélsior, 1 de septiembre, 1945, 16.

${ }^{52}$ El Universal, 16 de agosto, 1945, 1.
} 
dijo que "La existencia de la bomba ha reducido las posibilidades de una tercera guerra mundial y nos ha dado una esperanza válida". ${ }^{53}$ En el ámbito internacional, los componentes químicos que sirvieron para la creación de la bomba - el uranio, especialmente- se convirtieron de repente en foco de interés, haciendo de Canadá y del Congo Belga en dos de los países de mayor relevancia estratégica. ${ }^{54}$

En los Estados Unidos, el sentimiento de alivio fue manifiesto no sólo por la finalización de la guerra, sino porque además se convertía en el ganador de la misma. Empero, las preguntas surgieron de inmediato. El mismo 9 de agosto, Excélsior compartía con sus lectores el siguiente cuestionamiento, a saber: “¿Perdonará el pueblo norteamericano todo esto fundándose en que todo es válido en la guerra y en el amor o, preso de la ira, se levantará y censurará este manchón sobre el honor, la tradición y el buen nombre de los Estados Unidos?". ${ }^{55}$ Estas percepciones de carácter ético ya surgieron en Japón tras el episodio de Hiroshima cuando, en una radiodifusión dirigida a Estados Unidos, el gobierno nipón manifestó que "el uso de la bomba atómica señala al enemigo para las edades por venir como el destructor de la justicia y de la especie humana". 56

A pesar de estas valoraciones, el racismo y sus implicaciones en contra del pueblo japonés no se hicieron esperar. Un reportero del bando aliado escribía en el periódico Excélsior:

En el Japón tendremos que luchar contra un pueblo fanático, convencido de su superioridad y de la 'alta protección' de sus dioses. Tiene, además, la convicción de que no ha sido vencido militarmente y de que su ejército estaba intacto al dictarse la orden imperial de cesar el fuego [...]. La única fortuna de esa gente semibárbara, con una ligera capa de civilización que salta con la uña, es el trabajo y un puñado de arroz, con algunas varas de tela bajo una casa de cartón, madera y papel. La vida no vale gran cosa para ellos, sin sus fanatismos, sin sus dioses, sin el lastre de todo lo que se les ha enseñado para explotarlos mejor. ${ }^{57}$

No hay duda de que el racismo explícito en estas palabras iba encaminado a justificar el uso de la bomba atómica en contra de los japoneses, además de apoyar las decisiones acordadas por la coalición aliada. Este afán por humillar a Japón no sólo quedó en el ámbito de las opiniones,

\footnotetext{
${ }^{53}$ Finney, introducción, 13.

54 “Terremotos artificiales en el Japón”, Excélsior, 7 de agosto, 1945, 12.

55 "No quedó", 11.

56 “Junta extraurgente del gabinete nipón para discutir cambios por la bomba de átomos", Excélsior, agosto 8 , $1945,13$.

${ }^{57}$ Cor Tracy, “Comentario internacional”, Excélsior, segunda sección, septiembre 3, 1945, 7.
} 
sino también de las acciones más inmediatas como la rendición japonesa y posterior ocupación estadounidense. El 8 de septiembre de 1945, al entrar el ejército estadounidense en Tokio, la bandera norteamericana fue izada como símbolo de la victoria sobre el Imperio japonés. La bandera fue la misma que ondeaba sobre el Capitolio de Washington el 7 de diciembre de 1941, cuando los japoneses, sin advertencia previa, arremetieron contra Pearl Harbor, arrastrando a los Estados Unidos a la guerra. ${ }^{58}$

Por su parte, el presidente Truman se convirtió para la mayoría de los estadounidenses en una figura relevante por llevar a su país a la victoria final y por convertirse en el nuevo poder mundial hegemónico. Un fehaciente ejemplo se dio cuando, en diciembre de 1945, Truman fue designado por la revista Time como el hombre del año. En su última edición anual, se decía lo siguiente: "El más grande de todos los grandes acontecimientos de 1945 fue la bomba atómica". 59

A partir del Proyecto Manhattan, uno de los debates que se abrió al seno de la ciencia estadounidense giró en torno al rol que debía ocupar el científico — por momentos convertido en una especie de criatura politica-, vista por muchos con un personaje determinante en la toma de decisiones políticas en la nueva era tecnológica. ${ }^{60}$

Otro impacto relevante con el cual tuvo que lidiar el gobierno de Washington, se dio en el terreno de la diplomacia internacional respecto al control y al uso de la energía atómica, tal y como se verá a continuación. La situación y el peligro que suscitó este invento científico provocó miedo e incertidumbre en cuanto a su uso. Un ejemplo de ello fueron las palabras de la viuda del presidente Roosevelt, en el sentido de que "si los Estados Unidos no podían entenderse con otras naciones, la primera bomba atómica en la guerra próxima caería en los Estados Unidos". 61

En cuanto a Japón, las bombas atómicas representaron, en primera instancia, un cambio geopolítico de consideración, ya que la conclusión de la guerra, como se mencionó anteriormente, implicó el fin del Imperio japonés en ultramar y la devolución

\footnotetext{
58 “Tokio fue ocupada hoy militarmente”, Excélsior, 8 de septiembre, 1945, 1.

${ }^{59}$ Time, 31 de diciembre de 1945, portada. Por ejemplo, tan sólo unos días antes, Excélsior titulaba uno de sus artículos "La atómica y Truman, en primer lugar", Excélsior, 27 de diciembre, 1945, 3.

${ }^{60}$ Finney, introducción, 18.

${ }^{61}$ Dorothy Thompson, "Las masas: bomba atómica", Excélsior, 20 de octubre, 1945, 3.
} 
de las posesiones que había acaparado en su rápida carrera expansionista. ${ }^{62}$ Japón volvía a ser un "reino" de pequeñas dimensiones: mermó su orgullo y sentimiento nacionalistas, ${ }^{63}$ y hasta emergió el temor de enfrentarse a una revuelta interna. ${ }^{64}$ Las bombas atómicas dieron como resultado que, por primera vez en 2000 años de historia japonesa, el extranjero profanara el sagrado suelo nipón. Tal espectáculo dejó atónitos a 75 millones de súbditos de Hirohito que creían a pie juntillas en la invencibilidad de su patria. ${ }^{65}$ Esta situación se acrecentó cuando los estadounidenses entraron al país tras la rendición japonesa, un hecho histórico que fue interpretado como un afán de cuestionar el carácter divino del emperador. ${ }^{66}$

\section{El control de la bomba atómica: el gran reto después de la Segunda Guerra Mundial}

El lanzamiento de las dos bombas atómicas trajo consigo implicaciones duraderas, comenzando por el gran impacto en la diplomacia mundial, especialmente, en la norteamericana. ${ }^{67}$ Después de Hiroshima y Nagasaki, la agenda global quedó marcada por la necesidad de establecer un control sobre la energía atómica, habida cuenta de que los Estados carecían de protocolos jurídicos para regular unos inventos científicos que, como pudo comprobarse, avanzaban a pasos acelerados y no precisamente en beneficio de la humanidad. No había duda de que la diplomacia se enfrentaba a un nuevo y determinante desafío, particularmente, porque una sombra de incertidumbre se apoderó sobre el horizonte de aquella posguerra ante la posibilidad de que el secreto atómico pudiera caer en manos

\footnotetext{
62 “La rendición del Japón”, Excélsior, cuarta sección, 12 de agosto, 1945, 5.

${ }^{63}$ Luis Lara Pardo, "La fuerza del Japón”, Excélsior, 5 de septiembre, 1945, 3.

${ }^{64}$ El Universal, 13 de agosto, 1945, 2.

${ }^{65}$ Este sentimiento nacionalista y patriótico de los japoneses se debía al sintoísmo, religión nacional donde se mezclan el dogma teológico y el histórico patriotismo. Según ésta, el emperador desciende de Amaterasu - la diosa del Sol - y sus súbditos participan de su esencia celeste. De dicho origen, los sacerdotes sintoístas deducían el derecho eminente del Imperio del Sol Naciente a dominar al mundo y desde luego a los blancos, seres de razas inferiores condenados a la esclavitud. Véase "Los blancos en Tokio", Excélsior, tercera sección, 2 de septiembre, 1945, 11.

66 "Se forma en Japón un gabinete liberal”, Excélsior, 8 de octubre, 1945, 1.

${ }^{67}$ Richard H. Rovere, "La bomba y la política internacional”, en Hiroshima, 123.
} 
equivocadas. ${ }^{68}$ Como veremos a continuación, no fue tarea fácil alcanzar un acuerdo sobre quién debía tener el control sobre el secreto atómico, una situación que vino a agravar el clima de tensión durante la Guerra Fría. Del debate originado se desprendieron un buen número de reflexiones éticas, muchas de las cuales siguen presentes a la fecha.

Como se ha visto más arriba, el final de la Segunda Guerra Mundial coincidió con el descubrimiento y utilización de la fuerza atómica como un arma de capacidad destructiva nunca antes imaginada. Desde entonces y hasta la fecha, no hay duda de que esta energía basada en la fisión controlada del átomo ha sido un poderoso elemento de perturbación de la conciencia y ha condicionado sobremanera el devenir de las relaciones internacionales. La nueva arma provocó las más diversas y encontradas especulaciones, destacando una de ellas por encima del resto: los poseedores del secreto atómico habían encontrado la solución final —única, indiscutible e irrebatible — a todos los conflictos sociales, a todas las disputas entre las naciones y a todas las diferencias ideológicas y políticas. Aquel país, o países, en posesión del secreto atómico tendrían la capacidad de erigirse como árbitros supremos del destino humano. A partir de agosto de 1945, la energía nuclear era símbolo de hegemonía mundial. ${ }^{69}$ "Con sólo arrojar dos o tres minúsculas cargas —escribió Ortiz Echague en las páginas de Excélsior - sobraría para someter a los reacios, convencer a los incrédulos y amansar a los más rebeldes". ${ }^{70} \mathrm{Y}$ esto se traducía en una curiosa paradoja, según la cual las mismas personas que habían lanzado la bomba, eran las que más temían por su seguridad si es que alguien más encontraba el secreto. El diario Evening Star sacaba a la luz el 30 de junio de 1946 un estudio realizado para el presidente Truman, en el que se estipulaba que los edificios estadounidenses no

\footnotetext{
${ }^{68}$ El sentimiento de vulnerabilidad se apoderó de la sociedad estadounidense a raíz de lo sucedido en Hiroshima y Nagasaki. He aquí el siguiente fragmento: "El número de muertes que podrían resultar de la detonación de una sola bomba atómica de 20 megatones sobre la ciudad de Nueva York, podría exceder diez veces el número total de bajas que han sufrido los Estados Unidos en todos sus campos de batalla en toda su historia anterior". Tom Stonier, Desastre nuclear (México: Editorial Diana, 1968), 19.

${ }^{69}$ He aquí la siguiente puntualización: "La bomba atómica en su actual estado de desarrollo eleva el poder destructor de un único bombardero a un valor que es 50 a 250 veces el anterior, dependiendo esto de la naturaleza y tamaño del blanco. La capacidad destructora [...] está fuera de toda duda. [...] Se necesitarían unas 200 salidas de aviones B-29 con explosivos de alto poder para igualar el efecto de una salida con bomba atómica. Éste fue el caso de Hiroshima y el de Nagasaki". Patrick Maynard Stuart Blackett, Miedo, guerra y la bomba atómica (México: España-Calpe, 1950), 75 y 76.

${ }^{70}$ Para este influyente periodista, la sola amenaza de la bomba atómica era garantía para "mantener a raya el totalitarismo", hasta convertirla en "una poderosa influencia para la conservación de la paz mundial". Fernando Ortiz Echagüe, "La bomba atómica", Excélsior, 18 de septiembre, 1945, 3.
} 
aguantarían una bomba como las lanzadas en Hiroshima y Nagasaki. ${ }^{71}$ Este reporte dejaba bien claro que los Estados Unidos estaban preocupados de que alguien más lograra recrear su arma de destrucción masiva, teniendo al conglomerado académico trabajando en este tipo de investigaciones y reportes para contabilizar el monto de los daños en el caso de una pérdida del control atómico. En uno de sus editoriales, El Popular avanzaba la siguiente idea: "La Historia Universal, de esa manera, se simplificaba súbitamente: ya no habría lucha de clases, ni política internacional, ni diplomacia, ni mucho menos necesidad de organizar la cooperación y el equilibrio mundiales: la bomba atómica lo resolvía todo de un solo golpe". 72

Dadas las circunstancias, el control de la energía nuclear se convirtió en un tema prioritario, de entrada, para disuadir la incertidumbre, aminorar el miedo y, sobre todo, para no deteriorar las relaciones internacionales más de lo que ya estaban. Así, las conversaciones alrededor del control sobre la bomba atómica fue uno de los temas más tratados por la diplomacia de posguerra, habida cuenta de que el nuevo artefacto había cambiado de manera radical el viejo concepto del "interés nacional”, agregándose un nuevo y determinante factor: la extinción humana como una posibilidad innegable. ${ }^{73}$

La división de opiniones se hizo patente cuando se planteó la pregunta sobre quién debía ser el depositario del conocimiento de todo aquello que giraba en torno a la energía nuclear. De una parte, estaban aquellos partidarios de un control exclusivamente estadounidense y, de la otra, quienes apoyaban la tesis de que fuera la Organización de las Naciones Unidas, de reciente creación, la que se hiciera responsable del control atómico a través del Consejo de Seguridad. Como vimos en el apartado anterior, la fabricación de la bomba atómica se hizo con el mayor secretismo y, por consiguiente, sin ningún tipo de intervención diplomática. Durante las primeras fases del Proyecto Manhattan, la bomba se concebía como un instrumento más de destrucción puesto al servicio de la guerra, aunque, como ardid diplomático y de poder por parte de los Estados Unidos, tenía que usarse también para mostrar y demostrar su existencia al Kremlin. $^{74}$ Años después, el presidente

\footnotetext{
${ }^{71}$ Evening Star, 30 de junio, 1946, 9.

${ }^{72}$ El Popular, 29 de octubre, 1945, 9.

${ }^{73}$ Rovere, "La bomba", 126 y 127.

${ }^{74}$ Ibid., 123 y 124. En palabras de Giovannitti y Freed, "los bombardeos atómicos no fueron, en realidad, las operaciones militares finales de la Segunda Guerra Mundial, sino la primera acción diplomática de la guerra
} 
estadounidense Dwight D. Eisenhower llegaría a decir que fue la bomba atómica, más que cualquier otra cosa, lo que impulsó a la diplomacia a trabajar adecuadamente. ${ }^{75}$

Día con día, el miedo y la incertidumbre se veían reflejados en los periódicos de la época. Desde las páginas de Novedades, Óscar Méndez Cervantes escribía lo siguiente: "La amarga verdad es que sobre el mundo presente se encuentra suspendida la mortal amenaza. No es posible evadir esta tremenda realidad. Físicos destacados lo reiteran en diversos tonos. Dentro de pocos años — dice alguno—, si ello no se remedia previamente, bastará que desde Rusia se oprima un botón para que ciudades enteras de este continente vuelen en pedazos. Todas las naciones — afirma otro- estarán saturadas de bombas atómicas para el año de 1955, si no se logra la unidad internacional”, para avanzar la siguiente valoración final: "El conocimiento del poder atómico ha hecho imperativo para el hombre encontrar un medio de evitar la guerra o traer la muerte y el desastre a grandes extensiones de la tierra". 76

Pero no sólo en los periódicos, sino también en algunos manuscritos jurídicos aprobados, se hizo sentir esta problemática planteada. Tal fue el caso del Acta McMahon, que autorizaba al gobierno para dar licencia a la creación de reactores nucleares con una finalidad civil. $^{77}$ Así, se partía del principio de que el gobierno estadounidense sería el guía para la creación de una tecnología de reactores que se consolidara económicamente y propiciara una industria en el sector capaz de sostenerse por sí misma. Sin embargo, y a pesar de esta intención, el programa de energía atómica para usos pacíficos continuaría cargando con la pesada memoria de Hiroshima y Nagasaki. ${ }^{78}$

La necesidad de establecer un control sobre el energía nuclear se hizo también patente al abordar su aprovechamiento para usos estrictamente pacíficos. ${ }^{79}$ La comunidad científica

fría. En otras palabras, que su objetivo no fue el Japón, sino la Unión Soviética”, Giovannitti y Freed, $L a$ decisión, 305.

${ }^{75}$ Rovere, "La bomba", 131.

${ }^{76}$ Novedades, 15 de octubre, 1945, 4.

${ }^{77}$ El Acta McMahon estipulaba lo siguiente: "El efecto del uso de la energía atómica para propósitos civiles sobre las estructuras social, económica y política actuales no puede determinarse. Sin embargo, es razonable anticipar que el dominio de esta nueva fuente de energía causará cambios profundos en nuestro modo de vida presente". Clinton P. Anderson, "Usos pacíficos de la energía atómica", en Hiroshima, 103.

${ }_{78}^{7 b i d e m .}$

${ }^{79}$ El obrerismo americano fue uno de los principales precursores de la utilización de la energía atómica para usos pacíficos, ya que podría mejorar la vida de los seres humanos y "ennoblecer su ocupación hasta un grado tal, que los inventos anteriores parecieran insignificantes". El Universal, 10 de agosto, 1945, 2. 
llegó a especular con la posibilidad del manejo de explosivos nucleares para alterar el curso de las corrientes marítimas, disipar el peligro de los huracanes e incluso de las erupciones volcánicas. ${ }^{80}$ Sin embargo, la responsabilidad última recaía sobre una clase política que, desde un principio, se percató de las enormes dificultades que enfrentaba a la hora de proscribir el empleo de la energía atómica para fines bélicos. Por lo tanto, los esfuerzos se encaminaron a la creación de una comisión de vigilancia, a la reglamentación para un uso pacífico y a la implantación de salvaguardas para proteger a los países pacíficos en contra de posibles agresiones de potencias expansionistas. ${ }^{81}$

El control de la energía atómica era visto por muchos como una tarea única y exclusiva de las Naciones Unidas, a través del Consejo de Seguridad, bajo el argumento de que un descubrimiento como la bomba atómica no podía ser monopolizado por un único país, sino que debía ser un patrimonio de todos. ${ }^{82}$ Sin embargo, el presidente Truman dio a entender que la fabricación de la bomba atómica debía permanecer en secreto por tratarse de un arma con un enorme potencial destructivo, en un contexto en el cual las tensiones y la incertidumbre por saber qué ocurriría con el secreto estaban en su máximo esplendor. Y aún en el caso de compartir con países aliados para un uso pacífico de la energía nuclear, "esas discusiones no serán concentradas con informaciones que den a conocer el proceso de manufactura de la bomba atómica". ${ }^{83}$ Dicho de otro modo, el secreto nuclear habría de quedar como monopolio exclusivo de Estados Unidos, esto es, en manos del país creador de la bomba atómica.

Sin embargo, aquello era una cuestión de tiempo. Se supo, por ejemplo, que Japón había realizado investigaciones sobre la bomba atómica durante la segunda gran guerra, aunque los experimentos fracasaron a causa de que los físicos japoneses llegaron a conclusiones erróneas y las súper fortalezas B-29 destruyeron el laboratorio de Tokio donde se llevaban al cabo las investigaciones. ${ }^{84} \mathrm{~A}$ su vez, en los círculos cercanos al presidente Truman se especulaba con que la Unión Soviética podía producir su propia bomba atómica en un lapso de cinco a diez años. ${ }^{85}$

\footnotetext{
${ }^{80}$ Anderson, "Usos pacíficos", 104.

81 "El uso de la energía atómica", Excélsior, 17 de noviembre, 1945, 13.

${ }^{82}$ Lara Pardo, "El uso", 4.

${ }^{83}$ El Popular, 5 de octubre, 1945, 2.

84 “Japón investigaba la fuerza atómica”, Excélsior, 26 de octubre, 1945, 2.

${ }^{85}$ Jay G. Hayden, "La bomba y los rusos", Excélsior, 22 de octubre, 1945, 3.
} 


\section{enn-claves}

El 3 de octubre de 1945, Truman pronunció un importante discurso ante el Congreso de los Estados Unidos, donde manifestó que el problema del control de la energía nuclear era tan urgente que no podía esperarse a que Naciones Unidas optara por una solución definitiva. "La esperanza de la civilización — declaró el presidente estadounidense - radica en la decisión de renunciar al empleo y desarrollo de la bomba atómica y en el de dedicar la energía únicamente a fines humanitarios. De otra forma, la única alternativa que puede haber será la de emprender una desesperada carrera por armarse que tal vez termine en un desastre".

A su vez, y en otro momento de su discurso, Truman advirtió que la liberación de la energía atómica constituía "un acontecimiento demasiado revolucionario como para ser considerado dentro del marco de las viejas ideas", por lo que "la civilización [exigía] que alcancemos en el menor tiempo posible un ordenamiento satisfactorio para el control de la energía atómica de modo que llegue a ser una influencia poderosa y eficaz en el mantenimiento de la paz mundial en lugar de un instrumento de destrucción". Finalmente, dejó el siguiente mensaje premonitorio: "La esperanza de la civilización se basa en la posibilidad de concluir acuerdos internacionales que lleguen, en lo posible, a la renunciación del uso y desarrollo de la bomba atómica". ${ }^{86}$

Con este nivel de apremio, en noviembre de 1945 se llegó finalmente a un acuerdo general en torno a los pasos que debían darse para que un grupo internacional tuviese bajo su responsabilidad la vigilancia de la fabricación de la bomba atómica ${ }^{87}$ Reunidos en cónclave, los jefes de gobierno estadounidenses, británico y canadiense acordaron un plan común para someter a control el empleo de la energía atómica, es decir, aquélla desencadenada por la desintegración del átomo. ${ }^{88} \mathrm{Y}$ esto, bajo el entendido de que la energía nuclear podía y debía aprovecharse para "fines pacíficos industriales y benéficos para el género humano". 89

El acuerdo mereció su aceptación por parte de la comunidad internacional. De hecho, el primer ministro de Canadá, Mackenzie King, llegó a manifestar que, para preservar a la

\footnotetext{
${ }^{86}$ Blackett, Miedo, 164 y 165.

87 “Truman y Attlee decidieron el destino de la bomba atómica”, Excélsior, 14 de noviembre, $1945,1$.

${ }^{88}$ Lara Pardo, "El uso", 4.

${ }^{89}$ Ibidem.
} 
civilización de una destrucción atómica, era "necesario renunciar hasta cierto grado a la soberanía nacional, con el fin de establecer alguna forma de gobierno mundial". 90

La cesión de soberanía nacional en beneficio de un gobierno mundial, capaz de supervisar la producción nuclear, no era un tema menor. El propio primer ministro canadiense declaró que la única solución para prevenir al mundo de la amenaza nuclear era que los Estados abandonaran sus tradicionales ideas sobre la soberanía. Así, cualquier plan conducente a controlar, reglamentar, inspeccionar o ilegalizar la energía atómica habría de exigir una modificación en la idea de que cada Estado nacional era la autoridad suprema dentro de su territorio. Si la solución pasaba por aquí, el problema de fondo era cómo encontrar la fórmula de cesión de esa parte de soberanía para la producción de la energía atómica. Dos opciones se pusieron sobre la mesa: la primera, la que obligaba a los Estados a renunciar a su derecho de veto — reconocido en la Carta de San Francisco de junio de 1945-, sometiéndose en un momento dado a las decisiones y juicios de una mayoría de Estados nacionales; la segunda, la que abogaba por gestar un marco regulatorio que obligara directamente a los individuos, lo que significaba su enjuiciamiento en cualquier lugar y bajo los principios del Derecho Internacional sin que su propio Estado pudiera garantizarle ningún tipo de inmunidad. ${ }^{91}$ Así, y en palabras del periodista y comentarista político estadounidense Walter Lippmann, si bien esta última propuesta no daba pie a la creación de un gobierno mundial, sí al menos "nos brindaría los fundamentos $[. .$.$] de una verdadera comunidad mundial de individuos que estuviera por encima$ de las alianzas y ligas de Estados soberanos". 92

Como era previsible, el problema planteado en torno al control atómico se vivió de manera diferente en aquellos países interesados en conseguir el secreto y en poder manejar la energía nuclear conforme a sus intereses geoestratégicos. Por ejemplo, la Unión Soviética de Stalin mostró su cautela en un principio hasta el grado de restarle importancia. Sin embargo, y una vez transcurrido poco más de un mes desde Hiroshima y Nagasaki, los rusos se posicionaron en la revista moscovita Tiempos Nuevos, dando a entender que la bomba atómica

\footnotetext{
90 “Control técnico y científico de la atómica para la paz”, Excélsior, segunda sección, 29 de diciembre, 1945, 1. Desde las páginas de Excélsior, Walter Lippmann defendió la tesis de la pérdida soberanía como un paso fundamental para "lograr el gobierno mundial", con "una legislatura y un poder ejecutivo mundiales". Éste, y no otro, debía ser el único camino que debían seguir los Estados para "hacer frente al problema con la solución más difícil, menos esperanzadora en su realización y tal vez menos deseable". Walter Lippmann, "La declaración atómica", Excélsior, 1 de diciembre, 1945, 3.

${ }^{91}$ Walter Lippmann, "Soberanía y bomba", Excélsior, 3 de diciembre, 1945, 3.

${ }^{92}$ Lippmann, "La declaración atómica", 3.
} 
no debía ser monopolizada "por una potencia o grupo familiar de potencias", porque eso significaría la obtención del dominio hegemónico mundial. Así, abogaron por entregar el invento a un consorcio internacional que lo custodiara como un instrumento imperativo de orden y como el medio más efectivo de entendimiento mutuo entre las naciones amantes de la paz. ${ }^{93}$ Tomando esto en cuenta, más adelante se acordó que se discutiría la cuestión atómica tomando en cuenta la sugerencia soviética. ${ }^{94}$

Por su parte, y como era de prever, Estados Unidos fue el más interesados en manejar el capítulo del control de la energía atómica conforme a sus intereses nacionales. En el diario estadounidense Evening Star se estipulaba que el control de la energía atómica era el suceso más importante en la vida ${ }^{95}$ y que, si no se llegaba a un acuerdo, otra bomba los iba a destruir en el marco de una nueva guerra atómica. ${ }^{96}$ Como vimos en párrafos anteriores, el miedo y la incertidumbre eran noticia de portada en los principales periódicos del momento, donde se podían leer titulares como: "Una sola bomba atómica podría destruir 40 millones de vidas en los Estados Unidos si fracasa la diplomacia internacional". 97 A ello se unían constantes declaraciones poco o nada alentadoras, como aquéllas de Robert P. Patterson, secretario de Guerra estadounidense: "Hasta que podamos estar seguros de que nuestras relaciones internacionales han progresado al punto de que la guerra no vuelva otra vez más a oscurecer el mundo, es imperativo que los Estados Unidos continúen vigorosamente con sus actividades de investigación y desarrollo en todas las ramas de la ciencia, vitales a la defensa nacional". 98 A futuro, el Departamento de Guerra abogaba por un control aliado de la bomba atómica, ya que, "si caía en malas manos, podría ser el arma ideal para un ataque a traición en el futuro". 99

Las discusiones sobre el control llegaron al Congreso de los Estados Unidos, quienes esperaban recomendaciones del presidente Harry S. Truman acerca de lo que debía hacerse con la bomba atómica. El senador Arthur H. Vandenberg, republicano de Michigan, pidió mientras tanto que se creara una comisión mixta, compuesta por seis miembros del Senado y otros tantos

\footnotetext{
93 Ortiz Echagüe, "La bomba atómica", 3.

${ }^{94}$ El Popular, 9 de noviembre, 1945, 2.

${ }^{95}$ Evening Star, 9 de junio, 1946, 5.

${ }^{96}$ Evening Star, 17 de julio, 1946, 7.

${ }^{97}$ El Popular, 27 de octubre, 1945, 5.

${ }^{98}$ Ibidem.

${ }^{99}$ Novedades, 3 de agosto, 1945, 2.
} 
de la Cámara, para que hiciera "un cabal y completo estudio e investigación referente al invento y manejo de la bomba atómica". A su vez, el senador McMahon, demócrata de Connecticut, presentó una iniciativa señalando que el uso y aplicación de la energía atómica debía ser "vigilados por el gobierno federal para beneficio del país", exigiendo además "la prohibición de la explotación privada del invento". 100

Mientras tanto, el Senado estadounidense venía recibiendo innumerables demandas de la población para que la bomba atómica fuera definitivamente proscrita mediante un convenio internacional, por tratarse de un arma "demasiado terrible para ser usada otra vez". ${ }^{101}$ Sin embargo, la tesis gubernamental se mantuvo firme, en el sentido de que la bomba atómica debía quedar bajo el estricto control de los Estados Unidos. Así lo dejaba en claro el periódico Excélsior, al reportar que gente en el país consideraban “como una misión sagrada la posesión por los Estados Unidos de esta nueva fuerza de destrucción. Y porque amamos la paz, los pueblos conscientes del mundo saben que esa confianza no será violada, que será una misión ejecutada fielmente". ${ }^{102}$ Dos días después, el Senado norteamericano acordó la creación de una comisión de nueve personas para el control de la bomba atómica y para velar por la preservación de los múltiples secretos de la energía nuclear. ${ }^{103}$

La tesis de que el control atómico quedase en manos de Estados Unidos mereció el beneplácito de la prensa mexicana. El periódico El Universal consideraba que el vecino del norte era — "por ahora" [sic] — uno de los países más seguros del mundo para conservar el secreto de la bomba atómica y una de las naciones "que menores probabilidades tienen de abusar de él”. No obstante, las dudas parecían emerger de dicha constatación, ya que la simple posesión del secreto llevaría a Estados Unidos a convertirse en "una potencia imperialista obligada a seguir de conquista en conquista para conservar la ventaja que tienen ahora". ${ }^{104}$ Por su parte, Excélsior era también partidario de que los norteamericanos fueras "custodios de la bomba atómica", si bien se hacía eco de las iniciativas estadounidenses por aquellos proyectos

\footnotetext{
100 "Propone Truman que el gobierno federal controle y vigile la fuerza atómica", Excélsior, 7 de septiembre, $1945,15$.

101 "Piden en el Senado de los Estados Unidos que se proscriba la bomba atómica", Excélsior, segunda sección, 2 de noviembre, $1945,1$.

102 “Cooperación mundial para proscribir el uso de la atómica”, Excélsior, 28 de octubre, 1945, 9.

${ }^{103}$ El Popular, 31 de octubre, 1945, 2.

${ }^{104}$ El Universal, 27 de octubre, 1945, 4 y 6.
} 
encaminados a averiguar lo que era "capaz de hacer ésta [bomba atómica] a los barcos de guerra, las ciudades y las personas". ${ }^{105}$ Ciertamente, y en materia de investigación, existían dos opiniones respecto a la forma en que la energía atómica debía ser estudiada: mientras que la primera abogaba por un uso para fines industriales, la otra sostenía que debía emplearse para la fabricación de bombas atómicas con el fin de "exterminar a Rusia antes de que Rusia los exterminara a ellos". 106

Por su parte, Gran Bretaña quería apoyar la investigación experimental en todos los aspectos vinculados con la energía atómica, tal y como hizo público el primer ministro Clement R. Atlee. ${ }^{107}$ Fue así como en el aeródromo de Harwell, cerca de Didcot, se empezó a construir la primera factoría del mundo para la obtención de energía atómica para usos de paz, volviendo la espalda a la producción de bombas atómicas para encadenar esta energía y hacerla útil para el progreso y el mejoramiento de la humanidad. ${ }^{108}$ Esto implicaba que Gran Bretaña debía ayudar a Estados Unidos a guardar el secreto de la bomba atómica como una garantía sagrada para conservar la paz, una de las premisas defendidas a fines de 1945 por el que fuera primer ministro británico y líder del Partido Conservador Winston Churchill. Para él, Gran Bretaña debía hacer "sus propias bombas atómicas y tenerlas aquí, aunque sean fabricadas en otras partes, lo más pronto posible". Afirmó que el futuro de la bomba atómica debía ser decidido por los parlamentos y los gobiernos responsables y no por los hombres de ciencia, "por ilustres o entusiastas que sean". ${ }^{109}$

Por de pronto, la tesis que gozaba de más adeptos era depositar la confianza en Naciones Unidas, lo que suponía quitar el monopolio del secreto y control atómicos a Estados Unidos. Sometidas las plantas industriales a la inspección internacional, se creía en ese entonces que se pondría el fin definitivo a la fabricación de bombas atómicas. ${ }^{110}$ La apuesta no sólo incluía el

\footnotetext{
105 “Tío Sam probará la espantosa atómica”, Excélsior, 12 de diciembre, 1945, 2.

106 "Sombríos augurios de guerra atómica, hace Arnold”, Excélsior, segunda sección, 19 de octubre, 1945, 6.

107 "Temen la destrucción atómica de las ciudades de EE. Unidos", Excélsior, segunda sección, 30 de octubre, 1945, 6. Recordemos que Inglaterra hizo su primera prueba nuclear el 2 de octubre de 1952 en la Isla de Montebello, cerca de Australia, en el Pacífico Sur.

108 "La energía atómica en los usos de la paz", Excélsior, 6 de noviembre, 1945, 13.

109 "Qué gran hombre, ese Stalin, pero no le den la bomba atómica, declaró W. Churchill", Excélsior, 8 de noviembre, 1945, 14.

${ }^{110}$ Fernando Ortiz Echagüe, "La atómica ha causado el más grave embrollo internacional”, Excélsior, 26 de noviembre, 1945, 6 .
} 
control de la energía nuclear, sino también, sobre todos los inventos científicos militarmente estratégicos que quedarían bajo la supervisión del Consejo de Seguridad de las Naciones Unidas. ${ }^{111}$

Recordemos que esta organización internacional se creó el 24 de octubre de 1945, y desde el primer día tuvo el gran reto de configurar el mundo de la posguerra, incluido el gran desafío de controlar la energía atómica. Tras una cruenta guerra mundial, fueron muchas las esperanzas depositadas en esta nueva organización. Según Excélsior, “es más importante, hoy que nunca, que la nueva agrupación internacional de seguridad se ponga a trabajar. Ahora se trata de la paz y la seguridad o de la destrucción total de la civilización". ${ }^{112}$ Si la bomba atómica había puesto fin a la Segunda Guerra Mundial, este artefacto pondría una negra y alargada sombra sobre el nuevo tiempo de posguerra.

Entre los partidarios de depositar la confianza en las Naciones Unidas se encontraba el primer ministro británico Attlee, ${ }^{113}$ tanto así que se creó un plan — mereció el nombre de Plan Attlee - para que el Consejo de Seguridad de la ONU concentrara los informes científicos con vistas a establecer un estricto control sobre la bomba atómica. Para ello se hacía la recomendación de que la organización fuera reforzada mediante una cooperación más estrecha entre los Estados Unidos, Gran Bretaña y la Unión Soviética. ${ }^{114}$ Por su parte, entre los hombres de ciencia se encontraban los partidarios de difundir el secreto atómico como pauta común para la normalización de las relaciones internacionales, a fin de que laboratorios, industrias e instalaciones militares pudieran tener libre acceso a la energía atómica, aunque bajo la estricta supervisión de las Naciones Unidas. ${ }^{115}$ Por ejemplo, el Dr. D. Q. Posin, encargado del Laboratorio de Radiación del Instituto de Tecnología de Massachusetts, abogaba por un plan maestro de control internacional, mediante el cual la producción de la energía atómica a gran escala se encontraría en una estación mundial aislada — se pensó en una isla lejana—, donde los sabios de las naciones interesadas pudieran reunirse allí e investigar sobre los pormenores de la energía atómica. Esta concentración espacial supondría que, "en ningún otro lugar del mundo debía concentrarse la energía atómica en cantidades que pudiera destinarse a fines militares". 116

\footnotetext{
111 “Decisiva arma para hacer la paz”, Excélsior, 8 de agosto, 1945, 1 y 2.

112 Ibidem.

113 "Truman y Attlee discuten acerca de la bomba", Excélsior, 11 de noviembre, 1945, 1.

114 Ibidem.

115 "No guardarán ya el secreto de la atómica", Excélsior, 14 de octubre, 1945, 15.

${ }^{116}$ El Popular, 21 de octubre, 1945, 2.
} 
El debate sobre el manejo, experimentación y control de la energía nuclear no sólo quedó en manos de políticos y científicos, sino también contó con la aportación de la sociedad civil, por ejemplo, a través de la Conferencia Mundial de la Juventud, celebrada a principios de noviembre de 1945. A su término, se consensuó un documento donde se exigía, primero, que el control de la energía atómica fuese internacionalizado y administrado por las Naciones Unidas; segundo, que los descubrimientos científicos y técnicos fuesen utilizados en bien de la humanidad, y, por último, que los criminales de guerra fuesen castigados sin demora. ${ }^{117} \mathrm{~A}$ su vez, no faltaron colectivos de sacerdotes, profesores, miembros de asociaciones culturales y de agrupaciones pacifistas, que alzaron su voz en contra del monopolio del "inhumano elemento de destrucción", reclamando su entrega a la jurisdicción internacional. Así, también se dio el caso de aquellos que abogaron por la desaparición de los archivos secretos que contenían planes, estudios y todo tipo de cálculos para la fabricación de la bomba atómica. ${ }^{118}$

Como vimos anteriormente, Estados Unidos fue partidario de ser el único guardián del secreto atómico y, en todo caso, hacían depender su revelación a la presencia de un marco de garantías, consensuado y aprobado por todas las naciones. ${ }^{119}$ De entrada, y esto es importante subrayarlo, ello significaba que sería la gran potencia norteamericana la que decidiría cuándo las condiciones eran las idóneas para compartir el secreto atómico. Así, y frente al requerimiento de una aprobación conjunta por parte de las naciones, los Estados Unidos se reservaban el derecho a veto, por más de que hubiera una mayoría en contra, dejando muy en claro que la gestión del control atómico ya se había convertido en un arma claramente ofensiva. Aquello no era sino una expresión de poder y fuerza de la nueva política estadounidense, ya que los Estados Unidos siguieron fabricando bombas atómicas, de la misma manera que en Inglaterra, y como se ha mencionado, Winston Churchill hacía la notificación de que su país debía también producir bombas atómicas. La discrepancia entre las palabras y los hechos era total. ${ }^{120}$

\footnotetext{
117 "Control universal de la energía atómica", Excélsior, segunda sección, 9 de noviembre, 1945, 1.

${ }^{118}$ Ortiz Echagüe, "La bomba atómica", 3.

${ }^{119}$ En palabras de Blackett, "en los meses que siguieron al estallido de las dos bombas atómicas en Japón, [se tuvo la convicción] de que las guerras contra las grandes potencias podían ganarse con fuerzas extremadamente reducidas, siempre que dichas fuerzas poseyeran una provisión adecuada de bombas atómicas". Blackett, Miedo, 131.

${ }^{120}$ El Popular, 24 de noviembre, 1945, 9.
} 
A pesar de todo esto, en noviembre de 1945, los Estados Unidos, Gran Bretaña y Canadá reconocieron que, si bien era indispensable intercambiar con ciertas naciones los conocimientos científicos en torno a la energía nuclear, se tornaba muy peligroso revelar el secreto de la fabricación de la bomba atómica en aquellos primeros momentos de la posguerra. Además, se reveló que sería creada una comisión especial en el seno de Naciones Unidas a fin de hacer desaparecer la amenaza atómica, precisando las proposiciones que debía hacer. ${ }^{121}$ Dicho comunicado estipulaba: "Estamos dispuestos a compartir sobre la base de la reciprocidad con las Naciones Unidas las informaciones detalladas sobre las aplicaciones industriales de la energía atómica en cuanto los medios de protección contra la utilización de sus propiedades destructivas puedan ser formulados". ${ }^{122}$

Aun así, el choque de opiniones era evidente en Estados Unidos. Por una parte, el presidente Truman anunciaba al Congreso que el control de la bomba atómica se encontraba en buenas manos y que nadie podía temer por un uso ilegal del secreto; por la otra, el jefe de la delegación norteamericana en las Naciones Unidas, Edward Stettinius, se mostraba partidario de que la bomba atómica, al igual que el resto de las armas modernas, debían quedar bajo jurisdicción exclusiva de Naciones Unidas, en su condición de organismo internacional encargado de la preservación de la paz. Eso sí, éste fijaba como condición indispensable un correcto funcionamiento de este organismo internacional. ${ }^{123}$

Sin embargo, a pesar de que Naciones Unidas surgió como resultado de grandes expectativas, la recién creada organización tendría mucho trabajo por delante para eliminar el gran escepticismo reinante tras la guerra, ya que la humanidad tenía muchos motivos para sentirse desilusionada en cuanto a la sinceridad y efectividad de los acuerdos internacionales como la ya mencionada Acta McMahon. En ese momento, las opiniones se centraban en que la organización pudiera invocar a los Estados a respetar la normatividad comunitaria e incluso a reclamar a sus respectivos gobiernos a que sus conciudadanos actuaran conforme al espíritu

\footnotetext{
${ }^{121}$ Las proposiciones eran las siguientes: “1) Extender a todas las naciones la información científica básica que puedan ser intercambiadas con un fin pacífico; 2) Establecer el control de la energía atómica en la medida necesaria para garantizar que su enemigo se limite a fines pacíficos; 3) Lograr la suspensión de las armas atómicas y de todas las armas bélicas que puedan destruir colectividades enteras y 4) Proteger a las naciones contra la mala fe y la agresión eventual garantizando la vigilancia de la fabricación de estas armas". El Popular, 16 de noviembre, 1945, 2.

${ }^{122}$ Ibidem.

${ }^{123}$ Ortiz Echagüe, "La bomba atómica", 3.
} 
común. Una violación de los acuerdos supondría incurrir en un crimen por el cual los individuos podían ser juzgados y castigados. ${ }^{124}$ Para muchas personas, el hecho de que Naciones Unidas guardara el secreto de la bomba atómica era la única manera de preservar la paz, ya que vigilaría puntualmente la maquinaria industrial y científica de "los agresores del pasado y posibles agresores del futuro" y, por consiguiente, "todo peligro de una futura conflagración quedaría eliminado". ${ }^{25}$

De cualquier modo, a nadie se le escapaba que Naciones Unidas sólo podía tener el control sobre la bomba atómica en la medida en que se diera la tan necesaria cooperación internacional. En los estertores de la Segunda Guerra Mundial, éste fue el verdadero mensaje que cruzó la faz de la tierra: "Debemos encontrar la paz o encontraremos la destrucción completa". ${ }^{126}$ Sin embargo, los resultados no llegaban y las naciones más poderosas, lejos de unirse, se inclinaban a una definitiva separación para dar lugar a lo que después sería conocida como la Guerra Fría. ${ }^{127}$ Ejemplo de esto se vio en la Conferencia Atómica de Washington, llevada a cabo en diciembre de 1945, donde se acordó llevar a cabo una división de los países miembros de la ONU en dos clases diferenciadas: los que afirmaban ser depositarios exclusivos de la bomba atómica y los demás, a quienes se les suponía ignorantes del secreto. Esto evidenció una peligrosa división, enteramente contraria a las ideas de cooperación que inspiraron la formación de la ONU. ${ }^{128}$

No obstante, los más tenaces internacionalistas se dieron cuenta de que era excesivamente utópica y hasta ridícula la idea de que los que poseían el arma atómica y sus múltiples secretos fueran a depositarlos en algún emporio del internacionalismo jurídico como Ginebra o La Haya. ${ }^{129}$ Y es que todo lo anteriormente mencionado se enfocaba a controlar y regular la investigación y fabricación en torno al artefacto nuclear. A su vez, pronto se barajó la idea de que el Consejo de Seguridad también controlase la extracción de uranio, por lo que las minas debían quedar bajo la supervisión de una comisión conjunta de representantes de

\footnotetext{
${ }^{124}$ Lippmann, "La declaración atómica", 3.

125 "La bomba atómica neutraliza el polvorín balcánico", Excélsior, 1 de septiembre, 1945, 16.

${ }^{126}$ El Popular, 27 de octubre, 1945, 1.

127 Ibidem.

${ }^{128}$ El Popular, 5 de diciembre, 1945, 9.

129 Araquistáin, "Intermedio", 4.
} 
otras naciones, con inspectores residentes en cada país donde existieran depósitos del mineral como, por ejemplo, el Congo Belga. ${ }^{130}$

A pesar de la bondad de la idea, y de las dificultades que enredaban cualquier propuesta de control sobre la energía atómica, los responsables de las relaciones exteriores de los Estados Unidos, Gran Bretaña y la Unión Soviética anunciaron en diciembre de 1945 los acuerdos a los cuales llegaron respecto a los gobiernos de Japón y Corea y sobre la vigilancia de Naciones Unidas en relación con la energía atómica. En un largo parte, los ministros propusieron que Naciones Unidas, por medio de sus organismos de seguridad y vigilancia, habrían de procurar que la energía atómica fuese usada únicamente para fines pacíficos. ${ }^{131}$

En resumen, el control de la bomba atómica venía siendo un tema muy difícil de manejar, y más tomando en cuenta de que Naciones Unidas no era sino un organismo internacional de reciente creación y con un nivel de desarrollo y hasta de compromiso institucional aún incipiente. Se trataba, eso sí, de un primer paso hacia la cooperación internacional, por medio de la cual los pueblos del mundo podían concebir nuevas instituciones y acuerdos que la paz y la seguridad requerían de ahí en adelante. ${ }^{132}$ En aquel tiempo de posguerra, aunque de antesala de la Guerra Fría, la diplomacia hubiera tenido una agenda de trabajo más fácil, si no fuera por la existencia de un arma tan devastadora como la bomba atómica. Esto hubiera sido así o, por el contrario, de haber encontrado una fórmula conjunta que la hubiera sometido a algún tipo de control internacional que, entre otras múltiples ventajas, la hubiera eliminado como factor determinante en las relaciones diplomáticas entre las grandes potencias. ${ }^{133}$

\section{El poder desatado del átomo: a modo de final}

\footnotetext{
${ }^{130}$ Herbert Hoover, "La bomba atómica”, Excélsior, 10 de octubre, 1945, 3.

${ }^{131}$ La llamada Comisión de la Vigilancia Atómica debía proceder con "la mayor diligencia" a investigar todas las fases del problema atómico y a "presentar recomendaciones". Excélsior, 28 de diciembre, 1945, 1. Todo hacía pensar, como así fue, que la Unión Soviética habría de conseguir el secreto atómico bien por la vía de la experimentación científica, bien por la vía del espionaje. En este último aspecto, y como planteó Justin Atholl, "el robo de secretos atómicos plantea nuevos problemas de espionaje. [...] Los rusos tenían un sistema de espionaje bien establecido por todo el mundo, capaz de adaptarse perfectamente a los nuevos problemas que plantea la investigación atómica”. Justin Atholl, Cómo se entera Stalin (Barcelona: Ediciones Destino, 1952), 20 y 206.

132 "Control técnico y científico de la atómica, para la paz”, Excélsior, segunda sección, 29 de diciembre, 1945, 1.

${ }^{133}$ Rovere, "La bomba”, 130.
} 
A decir verdad, y desde la década de los cincuenta hasta la fecha, se han ido poniendo los cimientos no sólo para el control de la energía nuclear con fines bélicos, sino para abrigar la firme esperanza de un mañana sin la bomba atómica. A este respecto, y de manera sucinta, reseñar que el 29 de julio de 1957 empezó a funcionar en Viena el Organismo Internacional de Energía Atómica, perteneciente a las organizaciones internacionales vinculadas con la ONU y cuyo fin último sería el fomento de la energía nuclear para fines de paz, salud y prosperidad en el mundo. El origen de este organismo internacional estuvo inspirado en el discurso que el presidente estadounidense Dwight D. Eisenhower pronunció en la Asamblea General de la ONU aquel 8 de diciembre de 1953 bajo el prominente título de “Átomos para la paz". ${ }^{134}$ El tema no fue menor, y por su contribución a la causa del desarme nuclear, su director general -Mohamed el-Baradei- fue merecedor en 2005 del premio Nobel de la Paz.

El 5 de agosto de 1963, y tras la crisis de los misiles cubanos, Estados Unidos, el Reino Unido y la Unión Soviética firmaron el Tratado de Prohibición Parcial de Ensayos Nucleares que, entre otros requerimientos, prohibía los ensayos nucleares en la atmósfera, bajo el agua y en el espacio. Si bien Francia y China, ambas potencias nucleares, se negaron a firmarlo, aquel compromiso fue verdaderamente promisorio, puesto que, tan sólo unos años después, en el marco de la Guerra Fría, tuvo lugar la firma - primero de julio de 1968, con entrada en vigor desde el 5 de marzo de 1970 - , del Tratado de No Proliferación Nuclear, a través del cual se prohibía a los "Estados no nucleares" la posesión, manufactura o adquisición de armas nucleares, mientras que los “Estados nucleares" — los Estados Unidos, Reino Unido, Francia, Rusia y China - se comprometían a evitar toda transferencia tecnológica sobre armas nucleares a los países no nucleares. La aspiración última de este tratado no era otra que el desarme nuclear total y definitivo.

Siguiendo con esta línea del tiempo, el 10 de septiembre de 1996, y previa aprobación de la Asamblea General de las Naciones Unidas - 158 votos a favor, 3 en contra y 5 abstenciones - tuvo lugar la firma del Tratado de Prohibición Completa de los Ensayos Nucleares, que venía a prohibir la ejecución de ensayos nucleares por parte de los países

\footnotetext{
134 Véase este discurso en http://world-nuclear-university.org/html/atoms_for_peace/ (consultado el 12 de marzo de 2020).
} 
firmantes. En la actualidad, este tratado fue firmado por 178 países de un total de 195, con la notable excepción, eso sí, de los Estados Unidos y China. ${ }^{135}$ Por último, el 7 de julio de 2017 , y después de largas negociaciones, la Asamblea General de las Naciones Unidas aprobó el Tratado sobre la Prohibición de las Armas Nucleares, un acuerdo internacional que persigue la prohibición de las armas nucleares en busca de su eliminación total. ${ }^{136}$ Aquellos lejanos “átomos para la paz” están abriendo paso a un nuevo y, al parecer, definitivo escenario de hoy basado en una categórica paz sin átomos.

De cualquier modo, y como se ha puesto de manifiesto en estas páginas, el lanzamiento de la bomba atómica sobre Hiroshima y Nagasaki en aquellos días de agosto de 1945 representó un antes y un después en la historia de la humanidad. El hongo atómico causó una profunda conmoción mundial que abrió paso a una nueva época de confusión, incertidumbre y de múltiples preguntas sin respuesta. De inmediato, la celebración de la victoria aliada dio paso a las dudas que se abrieron en torno al control de aquel artefacto nuclear. Estados Unidos había demostrado su hegemonía científica y militar, aunque acabarían siendo los primeros en percatarse de que aquella primicia tecnológica tenía un carácter estrictamente momentáneo y que, tarde o temprano, la fórmula de la fisión del átomo quedaría en manos de otras potencias aliadas o rivales. ${ }^{137}$

De ahí la tesitura que se planteó en aquel otoño de 1945, y de la que aquí hemos dado cuenta, de si Estados Unidos debía quedarse con el secreto y control de la bomba atómica o si debía quedar bajo la custodia de un organismo internacional de reciente creación como Naciones Unidas, con el fin último de evitar un nuevo Hiroshima o Nagasaki. Desde el punto de vista racional, la respuesta más lógica era que, más allá de su erradicación por completo, la energía atómica pudiera controlarse de manera adecuada para múltiples usos civiles, entre otros, para fines médicos. $^{138}$

\footnotetext{
${ }^{135}$ Véase https://www.ctbto.org/ (consultado el 12 de marzo de 2020).

136 Véase el contenido del tratado en https://undocs.org/A/CONF.229/2017/8 (consultado el 12 de marzo de 2020).

${ }^{137}$ En el mencionado discurso de Truman del 3 de octubre de 1945, no dudó en advertir al Congreso estadounidense de lo siguiente: "Parece haber unanimidad en la opinión científica acerca del hecho de que todo el conocimiento teórico esencial, sobre el cual se basó el descubrimiento, es ya ampliamente conocido en todas partes". Blackett, Miedo, 164 y 165.

138 Por ejemplo, tan sólo unos años después, 30 isótopos diferentes se empleaban para diagnosticar enfermedades, a la vez que media docena se aplicaban en tratamientos. A su vez, los isótopos radioactivos de cobalto o cesio se empleaban para combatir cánceres profundos. Anderson, “Usos pacíficos”, 112.
} 
Por todo ello, la bomba atómica fue el tema central de aquel tiempo de posguerra. No faltaron quienes abogaron por su total erradicación para que nunca más se diera la posibilidad de fabricar un artefacto igual o de similares características. Ciertamente, los Estados Unidos fueron los que gozaron del privilegio de conocer la fórmula de la fisión de átomo para un uso militar. Para conocimiento de todos, Little Boy y Fat Man fueron sus dos grandes creaciones. Su monopolio fue incontestable, al menos, hasta el 29 de agosto de 1949 cuando los rusos hicieron estallar su primer artefacto nuclear: su RDS-1.

Mucho se ha usado el argumento de que la bomba atómica ayudó a que la Segunda Guerra Mundial terminara más rápido y a que Japón se rindiera de manera definitiva, logrando así que muriera menos gente de la que hubiera perecido si ésta se prolongaba. Sin embargo, desde el año de 1943 la suerte del Eje Roma-Berlín-Tokio estaba sellada. En Stalingrado, los soviéticos habían contenido ya a los alemanes y por el frente del Pacífico la marina había advertido al Emperador Hirohito, en ese mismo año, que la derrota de Japón era inevitable. ${ }^{139}$ Ahora sabemos que Japón ya se encontraba muy debilitado y la estrategia militar no requería del uso de la bomba para obtener su rendición, ${ }^{140}$ ya que la derrota se había acelerado sólo unos días o semanas, o a lo más unos cuantos meses y que los japoneses se habrían rendido pronto sin necesidad de la bomba o de la ocupación soviética. Los japoneses mismos - escribe Toshikazu Kaze - creen que "la rendición hubiera llegado a su debido tiempo, aun sin el terrible castigo de la bomba o la impresión del ataque ruso". ${ }^{141}$

Con esta aseveración final, que nos invita a reflexionar sobre si en realidad era necesario lanzar la bomba atómica, ponemos el punto final a estas páginas. El problema del control de la bomba atómica acabó siendo un arma diplomática $-\mathrm{y}$ de poder-, que tuvo su particular carácter ofensivo, más aún cuando aquel tiempo de paz pronto daría lugar a un enfrentamiento simbólico entre dos grandes bloques antagónicos liderados por Estados Unidos y la Unión Soviética, ambas potencias con una capacidad nuclear para una destrucción de impredecibles consecuencias. Para mediados del siglo XX, la amenaza del exterminio de la vida había ensombreciendo el planeta. Por eso, y parafraseando a Albert Einstein, el poder desatado del átomo lo había cambiado todo $\mathrm{y}$, por consiguiente, la humanidad podía deslizarse hacia una

\footnotetext{
${ }^{139}$ Baltazar, La era atómica, 3.

${ }^{140}$ Finney, introducción, 14.

${ }^{141}$ Baldwin, "La decisión sobre Hiroshima", 58.
} 


\section{enn-claves}

catástrofe sin paralelo. Tal vez, los científicos responsables de la creación del artefacto atómico debieron hacer lo mismo que Leonardo da Vinci al inventar el primer submarino de la historia, esto es, romper los planos por temor a que el hombre lo utilizara para destruir la civilización. ${ }^{142}$ Desgraciadamente, el género humano no pensó como Leonardo.

${ }^{142}$ Frank O’Brien, “Conclusión Catastrófica de la Presente Guerra”, 8 de Excélsior, agosto, 1945, 3. 


\section{Bibliografía}

Anderson, Clinton P. "Usos pacíficos de la energía atómica". En Hiroshima, veinte años después. México: Editorial Novaro, 1966.

Andrés, Gabriel E., “The International Atomic Energy Agency's Safeguards System”. International Law, núm. 11 (2008): 87-118.

Apikyan, Samuel, y David Diamond. Nuclear Power and Energy Security: NATO Science for Peace and Security. Armenia: Springer, 2009.

Atholl, Justin. Cómo se entera Stalin. Barcelona: Ediciones Destino, 1952.

Baldwin, Hanson W. "La decisión sobre Hiroshima”. En Hiroshima, veinte años después. México: Editorial Novaro, 1966.

Baltazar Ayala, Víctor Manuel. La era atómica. Guanajuato: Imprenta Universitaria, 1996.

Blackett, Patrick Maynard Stuart. Miedo, guerra y la bomba atómica. México: España-Calpe, 1950.

Carpintero, Natividad. La bomba atómica. El factor humano en la Segunda Guerra Mundial. Madrid: Editorial Díaz de Santos, 2012.

Ferguson, Charles. Nuclear Energy: What Everyone Needs to Know. Oxford: Oxford University Press, 2011.

Finney, John. "Introducción”. En Hiroshima: veinte años después. México: Editorial Novaro, 1966.

Gigon, Fernand. Horror en cadena: apocalipsis del átomo. Barcelona: Seix Barral, 1960.

Giovannitti, Len, y Fred Freed. La decisión de lanzar la bomba. Barcelona: Editorial Diana, 1968.

Hernández-Flórez, Cristhian E. "Tecnología nuclear: una historia de catástrofes y progresos”. Revista Médicas UIS, 25, núm. 3 (2012), 179-187.

Lapp, Ralph E. “La carta de Einstein”. En Hiroshima, veinte años después. México: Editorial Novaro, 1966.

Preston, Diana. Antes de Hiroshima: De Marie Curie a la bomba atómica. México: Sevilla Editores, 2008.

Rovere, Richard H. "La bomba y la política internacional”. En Hiroshima, veinte años después. México: Editorial Novaro, 1966. 


\section{enn-claves}

Smyth, Henry de Wolf. La energía atómica al servicio de la guerra: informe oficial del desarrollo de la bomba atómica realizado con el patrocinio del gobierno de los Estados Unidos durante el periodo 1940-1945. México: Espasa Calpe, 1946.

Smyth, Henry. La energía atómica para fines militares. México: Universidad Autónoma Metropolitana, 1995.

Stonier, Tom. Desastre nuclear. México: Editorial Diana, 1968. 